\title{
Prática e Formação: Psicólogos na Peritagem em Porte de Arma de Fogo
}

Practice and Training: Psychologists Active in Expertise of Firearm Usage Licensing

Desafíos en la Práctica y Formación de los Psicólogos Activos con Concesión de Licencia de Arma de Fuego

Julia Carolina Rafalski \& Alexsandro Luiz de Andrade

Universidade Federal do Espírito Santo

http://dx.doi.org/10.1590/1982-370301472013 
Resumo: Com o desenvolvimento e a crescente atualização da Avaliação Psicológica como área, prática e formação, os diferentes desafios enfrentados pelos psicólogos atuantes nesta temática têm sido discutidos. É pouco comum, contudo, a discussão das práticas e competências dos profissionais que atuam na Concessão de Porte de Arma de Fogo. Com o objetivo de conhecer estas atividades e este contexto de trabalho, foram entrevistados 14 psicólogos atuantes como peritos em concessão de porte de arma de fogo em um estado do Sudeste, sendo todos do sexo feminino, com idades entre 30 e 60 anos ( $M=39,1$ anos, $\mathrm{DP}=7,1$ anos). Os resultados apontam que a falta de formação voltada para a peritagem em porte de arma de fogo, bem como a formação deficitária em Avaliação Psicológica, podem conduzir a percepções negativas dentro deste contexto de atuação. A preocupação burocrática e documental que envolve esta avaliação, a falta de parâmetros para avaliação de perfil dos avaliados e o problema do descrédito do psicólogo como avaliador surgiram como temáticas adjacentes, suscitando a discussão do papel da formação na disseminação de melhores práticas profissionais.

Palavras-chave: Avaliação psicológica. Ética profissional. Testes psicológicos. Arma de fogo.

\begin{abstract}
Of study, practice, and training, the various challenges faced by psychologists working in this area have been discussed. However, discussion of the practice and skills of professionals working in the licensing of firearm usage is unusual. In order to improve understanding of these activities and this study, we interviewed 14 psychologists acting as experts in licensing the possession of firearms in a southeastern state of Brazil. All subjects were female aged 30-60 years $(M=39.1$ years; $S D=7.1$ years). The results indicate that a lack of training in expertise in possession of a firearm as well as a training deficit in Psychological Assessment may lead to negative perceptions within this context of action. Bureaucratic and documentary concerns surrounding this assessment, the lack of parameters to evaluate candidate profiles, and the problem of discredit of psychologists as evaluators emerged as key themes, leading to a discussion of the role of training in the dissemination of best practices.
\end{abstract}

Keywords: Psychological assessement. Professional ethics. Psychological tests. Firearms.

Resumen: Con el desarrollo y la creciente actualización de la evaluación psicológica como área, la práctica y la formación, se han analizado los diferentes retos que enfrentan los psicólogos que trabajan en este tema. No es habitual, sin embargo, la discusión de la práctica y las habilidades de los profesionales que trabajan en la Concesión de Licencia de Armas. Para conocer estas actividades y su contexto de trabajo, entrevistamos a 14 psicólogos que actúan como expertos en el otorgamiento de la posesión de un arma de fuego en un estado del sudeste, todas ellas mujeres, con edades comprendidas entre 30 y 60 años $(M=39,1$ años, $\mathrm{SD}=7,1$ años). Los resultados indican que la falta de capacitación dirigida a expertos en posesión de un arma de fuego, así como el déficit de formación en evaluación psicológica puede llevar a percepciones negativas dentro de este marco de acción. La preocupación burocrática y el documental que rodea esta evaluación, la falta de parámetros para evaluar el perfil del problema y del psicólogo desacreditado, evaluado como evaluador, surgió como temática subyacente, planteando el debate sobre el papel de la formación en la difusión de las mejores prácticas.

Palabras clave: Evaluación Psicológica. Ética profesional. Pruebas psicológicas. Armas de fuego. 


\section{Introdução}

A criação e utilização de artefatos como forma de proteção ou de ataque remetem aos nossos antepassados, ocorrendo somente no ano de 1888 a invenção da primeira metralhadora, uma arma de fogo portátil, por norte-americanos (Cotrim, 2002). Assim como as armas possuem um passado longínquo, também a Avaliação Psicológica (AP) se encaixa nesta posição: registros apontam para relatos de uso dos primeiros testes psicológicos na seleção de funcionários civis na China (Dubois, 1970, apud Pasquali, 2009). Existem também notas na literatura de que os primeiros testes, simples, com estruturas frágeis e falhas, foram criados no final do século XIX (Noronha, Beraldo \& Oliveira, 2003).

\section{Avaliação psicológica: um campo em construção}

A Avaliação psicológica (AP) é um processo de investigação que visa conhecer fenômenos psicológicos (Cruz, 2004) facilitando a interação entre os indivíduos e proporcionando maior segurança para as decisões profissionais nas áreas em que se insere. Conforme Noronha e Alchieri (2004), é um exame realizado para responder a questões específicas ligadas ao funcionamento psíquico adaptado de um indivíduo, com o objetivo de avaliá-lo em determinado período e/ou predizer possíveis modos de funcionamento psicológico futuros. Para Primi (2003), é considerada a integração entre a ciência e a prática profissional do psicólogo.

Teste psicológico, em si, é entendido como um instrumento padronizado e objetivo, utilizado de forma indireta para mensurar os fenômenos e processos psicológicos por meio da averiguação do comportamento humano (Joly, Berberian, Andrade \& Teixeira, 2010). Já a AP explicita a junção de diferentes instrumentos de avaliação, não necessariamente utilizando testes psicológicos, para produzir um conhecimento mais aprofundado sobre determinado indivíduo (Ocampo, Arzeno \& Piccolo, 1981). Tavares (2003) demostra com o conceito de Validade Clínica que a validade da AP não está ligada à validade dos instrumentos, e sim às associações qualitativas inferidas a partir das relações encontradas entre as informações obtidas. Dessa forma, a utilização de testes psicológicos ou outros instrumentos não implica a realização de um processo de $\mathrm{AP}$, uma vez que é a análise crítica resultante da junção dos dados quantitativos e/ou qualitativos que produz conhecimento sobre o indivíduo e possibilita discussões embasadas sobre o perfil psicológico.

Segundo Yamamoto (2012), 32,9\% dos psicólogos inseridos no setor público (do contingente total registrado no Sistema Conselhos) atua com a aplicação de testes psicológicos, sendo este número igual a $23,5 \%$ no terceiro setor. Noronha (2002) verificou, em pesquisa com psicólogos de São Paulo, que 25,9\% da amostra pesquisada considera o mau uso dos instrumentos psicológicos como um dos problemas mais graves que ocorrem na área de Avaliação Psicológica. Foram descritos como exemplos de mau uso dos instrumentos a avaliação incorreta por parte do psicólogo, a falta de clareza na aplicação, o erro de aplicação e o erro de avaliação. Erros como os citados impactam não somente a atuação dos psicólogos, mas também sua credibilidade perante a sociedade, que desqualifica a utilização dos testes psicológicos com base nas ações de profissionais que por falta de conhecimento prejudicam a qualidade das informações obtidas.

O mau uso dos instrumentos psicológicos reforça a necessidade de constante reflexão sobre estas práticas, mas de forma construtiva, com o objetivo de diminuir a carga de preconceito existente (Primi, 2010). Desde sua instituição como prática privativa da categoria dos psicólogos (Resolução Conselho Federal de Psicologia (CFP) 012/00 e Lei n 4.119 de 27 de agosto de 1962 [alínea "a", do parágrafo $1^{\circ}$ do artigo 13]), esta sofre com as críticas que reprovam sua utilização em processos individuais e de massa, principalmente nas áreas de Recrutamento e Seleção e no âmbito da Psicologia do Trânsito.

O campo da Avaliação Psicológica tem se desenvolvido de modo crescente, deixando de ser percebido como fato isolado 
e se tornando um processo que combina diferentes técnicas e métodos, entre eles os testes psicológicos, as entrevistas, observação e análise sócio-históricas (Trevizan, 2011). Almeida (1999), julgava que os instrumentos psicológicos não haviam acompanhado o desenvolvimento das demais áreas de conhecimento, como a informática ou a tecnologia, em franca expansão naquele momento. Após quase 15 anos, pode-se perceber a notável evolução dos instrumentos, baseada em inovações estatísticas, como por exemplo os adventos da teoria de resposta ao item (TRI) e da testagem adaptativa computadorizada (CAT), na ampliação de pesquisas e, principalmente, na produção de instrumentos nacionais, já adaptados para população brasileira. É importante frisar que a evolução do processo de AP deu-se também em relação aos aspectos éticos e legais da área, com a criação do Sistema de Avaliação dos Testes Psicológicos, o SATEPSI, pelo Conselho Federal de Psicologia, em 2003.

\section{Avaliação psicológica e porte de arma}

Em consonância com o desenvolvimento dos processos de AP, as Legislações sobre Armas de Fogo tiveram início na década de 1990 com a criação e instituição do Sistema Nacional de Armas (SINARM) por meio da Lei $n^{\circ}$ 9.437, de 20 de fevereiro de 1997. Em 2003, a lei então existente foi revogada ao ser instituída a Lei $\mathrm{n}^{\circ} 10.826$, de 22 de dezembro de 2003, conhecida como o Estatuto do Desarmamento, que dispõe sobre o registro, porte e comercialização de armas de fogo e munição, sobre o SINARM e sobre as providências cabíveis aos crimes desta alçada. Conforme apontado por Pellini (2006), esta nova legislação trouxe mudanças significativas ao contexto do porte de arma, como a alteração da idade mínima, de 21 para 25 anos, a exclusividade de concessão de porte pela Polícia Federal e a instituição de crime inafiançável para os infratores que portarem armas não registradas e sem porte próprio.

Ainda que houvesse a instituição da necessidade da AP para obtenção do porte de arma, não foram instituídas, à época, legislações sobre a atuação do psicólogo neste contexto. $\mathrm{O}$
Conselho Federal de Psicologia (CFP), diante da falta de legislações que normatizassem ou respaldassem a atuação do psicólogo, promulgou em 2008 a resolução no 18 (CFP, 018/2008), dispondo sobre o trabalho do profissional de Psicologia na Avaliação Psicológica para concessão de registro e/ou Porte de Arma de Fogo. Considera, ao promulgar a resolução, a necessidade de normatizar e qualificar os procedimentos relativos ao registro e porte de arma de fogo, adicionando em conta a importância da avaliação psicológica como processo obrigatório e eliminatório. Tal legislação visa prevenir que candidatos que possuam características incompatíveis com o porte de arma não obtenham esta autorização por meio da avaliação de traços de personalidade e atenção.

Atualmente estão cadastrados 1.088 profissionais Psicólogos Peritos em Avaliação para Concessão de Porte de Arma de Fogo, divididos de forma desigual entre os Estados de nossa Federação. Em divisão regional, estão cadastrados 82 profissionais na Região Norte, 166 na Região Nordeste, 200 na Região Centro-Oeste, 374 na Região Sudeste e 266 na Região Sul (Polícia Federal, 2013). A disparidade fica mais visível ao se relacionar a amplitude entre os números de profissionais: O Estado da Paraíba conta com 4 profissionais peritos, enquanto o Estado de Minas Gerais possui 186 profissionais peritos, o que, guardadas as devidas proporções entre o número de inscritos em cada Conselho Regional de Psicologia, demonstra grande disparidade.

Ainda que se pretenda realizar o controle e a restrição da obtenção de armas de fogo, como explicitado por Pellini (2006), não há no Brasil até o presente momento, uma definição de perfil psicológico de candidatos para a obtenção do Porte de Arma de Fogo. Conforme Primi (2010), a Avaliação Psicológica é um complexo processo, que busca sistematicamente conhecer o funcionamento psicológico das pessoas de forma a orientar ações futuras. Neste sentido, possui, em casos específicos, a função de gerar indicações preditivas sobre o comportamento do indivíduo, como em situações de controle emocional para manuseio de armas de fogo, habilitação para condução de veículos de carga, entre outros. 
Levando em consideração a existência de pouca produção científica sobre avaliação psicológica para concessão de porte de arma de fogo, este trabalho tem como objetivo conhecer as práticas, competências e aspectos de formação dos profissionais que atuam no campo da avaliação pericial. Uma vez que, segundo Tavares (2012), a interação entre o profissional de Psicologia e o avaliado possui influências nos resultados das avaliações, é importante observar os fatores de competência e formação que podem promover boas práticas e facilitar a realização do processo avaliativo.

\section{Metodologia}

\section{Participantes}

Entre os profissionais cadastradores atualmente em todo o território nacional, existem 35 (trinta e cinco) psicólogos credenciados pela Polícia Federal no estado escolhido para a realização da pesquisa. Para composição da amostra, os profissionais foram contatados por meio dos telefones disponíveis na lista divulgada pela Polícia Federal e convidados a participar da pesquisa, após explicação dos objetivos e envio de carta-convite por e-mail.

Entre os profissionais cadastrados na Polícia Federal do estado de realização da pesquisa $(n=35)$, apenas 14 se dispuseram a participar. Dois profissionais não demostraram interesse em participar por não estarem presentemente atuando com porte de arma de fogo, sendo que os demais não retornaram aos contatos para agendamento de entrevista ou declinaram no momento do convite. Todas as 14 participantes eram do sexo feminino, com idades entre 30 e 60 anos, com média de 39, 1 anos (DP $=7,1$ anos). Entre os profissionais, nove obtiveram o grau de psicólogas pela Universidade Federal do estado pesquisado

\section{Instrumentos}

Roteiro de entrevista para Psicólogos(as) Peritos(as)

O roteiro para obtenção de informações sobre o trabalho em concessão de porte de arma de fogo foi formado por 21 questões, que abrangiam perguntas sobre a formação dos participantes, a obtenção do título de perito e os requisitos necessários para o procedimento, as práticas de avaliação psicológica executadas pelos profissionais, as particularidades da avaliação do candidato ao porte e os desafios e influencias na área. Para este trabalho, realizou-se um recorte com 11 questionamentos sobre a inserção dos psicólogos na área de Porte de Arma de Fogo, suas especificidades e desafios.

Procedimentos de coleta e análise de dados Inicialmente, submeteu-se a proposta de pesquisa ao Comitê de Ética em Pesquisa com seres humanos, obtendo aprovação ( ${ }^{\circ}$ 38.767). Posteriormente à sua aprovação, foi realizado contato por telefone e agendamento de entrevista com os participantes, os quais foram entrevistados em seus locais de trabalho, possibilitando o conhecimento do ambiente profissional destes. Foram assinados os Termos de Consentimento Livre e Esclarecido em duas vias, pontuando a confidencialidade da pesquisa e a possibilidade de se retirar do estudo sem ônus, caso não se sentissem à vontade para prosseguir.

As entrevistas ocorreram no período de julho a setembro de 2012, tendo sido gravadas com a permissão das participantes e transcritas para fins de análise. Para a análise dos dados coletados, utilizamos a análise de conteúdo das respostas obtidas via considerações de Bardin (1994), cujo entendimento é que este procedimento deve ser utilizado para a interpretação daquilo que emerge da fala dos sujeitos e não apenas para proceder a uma descrição do conteúdo das respostas emitidas. Para tanto, foram criadas categorias referentes às respostas de cada questionamento, dentre as quais se destacam: "motivo de atuação com porte de arma de fogo", "número de avaliações realizadas", "características avaliadas no processo", "pontos abordados na entrevista com candidatos", "condições para apto e inapto", "principais desafios na área" e "mudanças ocorrentes na Avaliação Psicológica". 


\section{Resultados e Discussão}

As participantes do estudo relataram atuarem há um longo período de tempo em Psicologia, com experiência que variou entre 10 e 42 anos $(M=20,7$ e DP $=9,5)$. Contudo, somente cinco participantes incluíram na somatória de seu tempo de experiência os anos em que atuaram como estagiárias, demonstrando que uma parcela das entrevistadas não levou em consideração o aprendizado obtido na prática durante a formação em Psicologia. Reppold e Serafini (2010) explicitaram a importância da prática de estágios durante a formação educacional, uma vez que após o desenvolvimento acompanhado das atividades é possível identificar dificuldades e erros, além de proporcionar a união entre a teoria e a prática profissional.

Atuo desde 1990, porque em 1989 eu ainda era estagiária, então desde 1990 mesmo. (Participante 05, 23 anos de formação)

Bom, eu comecei a atuar desde o $2^{\circ}$ período de estágio. Então eu fiz todos os períodos de estágio do $2^{\circ}$ ao $10^{\circ}$ período. E desde a partir do momento que eu me formei, eu atuo como profissional. (Participante 13, 19 anos de formação)

Essa é uma pergunta muito pesada... eu faço estágio desde o $4^{\circ}$ período da faculdade, eu considero uma atuação, que foi onde eu mais aprendi... eu entrei na faculdade em 1986... então desde 1988. (Participante 02, 27 anos de formação)

As participantes demonstraram, também, preocupação com a formação continuada, sendo que todas as 14 psicólogas entrevistadas possuem cursos de Pós-Graduação ou Especialização. As profissionais citaram a realização de cursos de curta duração, chamados de formações ou reciclagens, principalmente sobre atualização e aprendizagem de testes psicológicos novos no mercado ou reformulados.

Quanto ao seu trabalho atual, seis das profissionais entrevistadas se classificaram como empresárias, pois possuem clínicas de Psicologia, empresas de recursos humanos ou clínicas credenciadas ao Detran para a realização de avaliação psicológica para obtenção de carteira nacional de habilitação. Quatro das profissionais entrevistadas relataram atuarem em dois empregos, sendo que em um deles permanecem em uma carga horária diferenciada.

Eu trabalho com tudo, é uma clínica que trabalha com avaliação psicológica e medicina do trabalho. Lá nosso principal carro chefe é a atender vigilantes, pessoas que vão fazer curso de vigilante, que vão fazer reciclagem, ou empresas de vigilantes, que tem que fazer os periódicos. Esse é o nosso trabalho principal lá. Você não precisa estar credenciado a polícia federal, mas não deixa de ser uma avaliação psicológica para porte de arma, já que esses vigilantes trabalham armados. Mas a única prerrogativa é que você esteja inscrito no CRP. (Participante 03, 19 anos de formação)

Sou professora de Avaliação Psicológica, trabalho com avaliação psicológica desde o meu $7^{\circ}$ período de Psicologia, mais precisamente na área de avaliação clínica. Trabalhei no mercado de trabalho também trabalhei com avaliação psicológica principalmente para porte de arma. Meu primeiro emprego foi trabalhar numa empresa de vigilância patrimonial no Rio. E, além disso, também trabalho na área de Psicologia Jurídica no qual trato com crianças e adolescentes vítimas de violência. (Participante 12, 17 anos de formação)

Em relação ao tempo credenciamento para atuação como Perito em porte de Arma de Fogo, pode-se perceber uma divisão quanto ao tempo de recebimento da permissão. Seis profissionais relataram que foram credenciadas no período entre 2010 e 2011 e as demais relataram possuir o título há cerca de 10 anos, tendo-o obtido entre 1999 e 2000 . Foi relatado, em adicional, o tempo elevado de espera para a obtenção do credenciamento, que é realizado esporadicamente devido à falta de psicólogos responsáveis pela fiscalização da documentação e dos registros, 
que atuam em Brasília como funcionários da própria Polícia Federal.

Olha, se não me engano, em torno de 2 anos. A gente já solicitou em 2007, 2008, mas até que a psicóloga de Brasília viesse e isso é sempre muito demorado, a gente só conseguiu agora em 2011, por aí. (Participante 08, 10 anos de formação)

Foi no início do ano passado (2011) quando eles estiveram aqui no estado. Então na prática aqui na clínica também faço avaliação para porte de arma. Quando eles estiveram aqui ano passado no estado eu já tinha toda a documentação, eu já tinha o tempo mínimo de formada, os cursos que eles pediram, e aí quando eles vieram eu encaminhei a documentação, fiz a inscrição, aí eles estiveram na clínica, fizeram fiscalização, entrevista e foi liberada a atuação. (Participante 13, 19 anos de formação)

As entrevistadas também frisaram a não-compatibilidade do nome utilizado para os profissionais atuantes na área, "Peritos em Porte de Arma de Fogo", uma vez que não existe uma formação a ser realizada para capacitar os psicólogos inscritos, seja promovida pelo Conselho Federal de Psicologia (CFP) ou pela Polícia Federal (PF). Como promulgado na Resolução do CFP no 013/2007. Para a aquisição do título de Especialista é necessário possuir o curso de formação da especialidade desejada em instituição cadastrada com carga horária superior a 500 horas, tempo mínimo de 2 anos de inscrição no Conselho Regional de sua localidade e a aprovação no concurso aberto para a especialidade requisitada. Diferentemente do realizado pela Polícia Federal, na Avaliação Psicológica em contexto de Trânsito, o Conselho Nacional de Trânsito (CONTRAN) assegura a necessidade do credenciamento de profissionais psicólogos peritos pelos respectivos órgãos de trânsito estaduais e institui a necessidade do Título de Especialista em Psicologia do Trânsito reconhecido pelo CFP para legitimar a atuação (Dagostin, 2006).

A Ordem de Serviço n ${ }^{\circ}$ 001/2004 do Ministério da Justiça e da Polícia Federal institui, em seu nono subscrito, que é um requisito para ser credenciado como psicólogo perito possuir o título de Psicólogo e estar em dia com anuidade no Conselho de sua região. Explicita, também, a necessidade de mínimo de três anos de exercício profissional e prática comprovada ou a posse de certificados de cursos nos testes a serem utilizados. Na alínea 9.3 é informado ainda que o credenciamento é valido por 2 anos, podendo ser renovado por igual período após fiscalização em loco.

Pois é. Perita para fazer avaliação psicológica, né? Porque você tem que estar inscrito na Polícia Federal, não tem nenhum título, tipo assim, você não faz nenhum curso pra isso. (Participante 03, 19 anos de formação)

Eu sou credenciada para fazer avaliações para porte de arma, mas não sou perita nisso, porque não tem um curso específico para isso. (Participante 04, 18 anos de formação)

Quanto ao processo de aquisição da certificação, 12 profissionais entrevistadas citaram a necessidade de encaminhar uma documentação para a Polícia Federal e cinco apontaram a necessidade de serem entrevistada pelos psicólogos da própria Polícia. Houve, também, a necessidade de comprovar a existência de um local para realização das atividades de avaliação psicológica e o conhecimento prévio dos testes psicológicos a serem realizados por meio da apresentação de diplomas de cursos de formação, apontada por sete participantes. Nenhuma das entrevistadas citou a necessidade de algum teste psicológico específico exigido, frisando somente que devem ser aplicados um teste de atenção, um teste de personalidade e um teste de inteligência/raciocínio. Quatro participantes citaram ainda que receberam um convite para realizar o credenciamento na Polícia Federal, ainda no início da atuação do órgão no cadastro de psicológicos. Outras duas participantes declararam conhecer funcionários da Polícia Federal e terem recebido a notícia do cadastramento para porte de arma de fogo por meio destes.

Para você ter o registro da Polícia Federal, você tem que entrar no site e tem lá todas as informações. Eu fiz da seguinte 
forma: a psicóloga da Polícia Federal, de Brasília, veio para o Estado para estar credenciando algumas pessoas e ai ela fez uma visita a minha empresa, fez uma entrevista comigo, me perguntando algumas coisas sobre os testes, o que eles mediam, tempo de aplicação... Então ela fez essa entrevista comigo, me entregou alguns materiais para serem lidos e depois que foi aprovado todo o trâmite, a documentação toda que eu entreguei, os cursos, os diplomas, eu recebi outro material também da Polícia. (Participante 01, 17 anos de formação)

Eles pedem alguns cursos, tem uma carga horária mínima que agora eu não lembro (40 horas, alguma coisa assim), e você apresenta o certificado para eles, tem que ter o tempo mínimo de formado... Aí eles fazem todo um questionário, toda uma entrevista, eles verificam várias informações pessoais. Eles fazem um treinamento também, uma reunião lá na Polícia Federal... Eles vêm aqui, fiscalizam, verificam se realmente tem aqueles testes no arquivo, se o espaço está adequado ao que eles precisam... (Participante 13, 19 anos de formação)

Pode-se perceber que existe uma uniformização dos procedimentos burocráticos e documentais para a obtenção do credenciamento para a concessão de porte de arma de fogo, porém no nível das competências de um psicólogo avaliador para porte de arma não são claros e objetivos os pré-requisitos de formação e conhecimento. A aquisição de competências que possibilitem o exercício ético e habilidoso de quaisquer atividades dentro da Psicologia devem ser apoiar em numa formação que garanta domínio básico das atividades no escopo de exercício da profissão psicólogo (Bernardes, 2012). É por meio da instituição de atividades de ensino que fortaleçam atuações diversas que o campo da prática se desenvolverá, bem como por meio da produção de conhecimento nas áreas específicas de atuação. Nesta direção, Noronha (2002), em pesquisa com 214 psicólogos do CRP $6{ }^{a}$ região, verificou que os problemas mais frequentes em relação aos testes psicológicos são relativos à formação dos profissionais, explicitando, à época, a necessidade de estabelecimento de parâmetros mais específicos para a formação na área. A uniformidade dos procedimentos visa promover maior confiança entre os resultados obtidos pelos profissionais, bem como a especificação de baterias de testes pré-definidas possibilitariam a comparação entre sujeitos e entre momentos de testagem, facilitando o não-credenciamento de profissionais que não se adequam aos parâmetros exigidos e a percepção de resultados atípicos nas avaliações.

Com relação aos motivos pelos quais decidiram atuar como peritas para concessão de porte de arma de fogo, 12 das profissionais entrevistadas citaram a possibilidade de aumentar a renda própria e a renda da empresa em que atuam, além de expressarem ser uma nova oportunidade de atuação. Cinco psicólogas também citaram o fato de já atuarem com Avaliação Psicológica em outras subáreas, além de oito terem expressado interesse e identificação com a área de atuação.

É um trabalho da nossa área, mais um trabalho em avaliação psicológica que você pode fazer e eu gosto dessa área. Eu comecei minha vida como psicóloga, fazendo avaliação, fiz estágios na área, na faculdade eu dei monitoria dessa matéria, sempre gostei de testes, estudei muitos testes, fiz muitos cursos na área, por causa disso. Eu acredito muito nas avaliações. (Participante 10, 27 anos de formação)

Eu vi como uma possibilidade de mais uma fonte de renda para o consultório, porque quando você trabalha com clínica você sabe que em uma época o consultório fica vazio. Ai seria uma outra possiblidade para manter a renda do consultório. Por me achar apta a aplicar testes, porque já fiz isso bastante quando era estagiária. Não com porte de arma, mas era aplicação, correção, elaboração de laudos, então me sinto habilitada a fazer isso. (Participante 04, 18 anos de formação)

Em relação aos testes comumente utilizados nas baterias de avaliação, o teste PMK (editora Vetor) foi citado como o principal instrumento 
para a concessão do porte de arma de fogo antes de ser considerado desfavorável para o uso profissional em julho de 2012 pelo SATEPSI, tendo sido lembrado por 13 das profissionais entrevistadas. Em seguida, como segundo instrumento mais citado, com 12 menções, figura o Palográfico (Editora Vetor), como uma opção para a substituição do PMK, uma vez que ambos representam instrumentos expressivos. Em terceiro lugar, os testes Zulliger (Casa do Psicólogo) e o Pfister (Casa do Psicólogo), ambos com oito menções. O teste IFP (Casa do Psicólogo), atualmente desfavorável para comercialização e uso, foi citado por cinco participantes. Os testes de personalidade menos lembrados foram o HTP (três menções), Quati (duas menções), TAT, CPS, Staxi e EFN, todos com apenas uma menção.

É possível notar uma diferenciação no uso dos instrumentos em relação aos últimos 10 anos. Em pesquisa publicada em 2003, Noronha, Beraldo e Oliveira elaboraram uma listagem com os instrumentos mais conhecidos por 52 profissionais de Psicologia, na qual o PMK figura como $19^{\circ}$, conhecido por 41 profissionais e o Palográfico como $40^{\circ}$, conhecido por 24 profissionais, sendo que o teste Pfister sequer figura na listagem. $\mathrm{O}$ teste Zulliger figura como o $3^{\circ}$ na listagem, lembrado por 48 dos 52 profissionais. Entretanto, os principais instrumentos apresentados pelos autores em 2003 não permanecem na lista de testes psicológicos aprovados para uso do SATEPSI atualmente, fato que pode ter influenciado a abertura a novos instrumentos e a popularização de testes pouco considerados para a realização de Avaliação Psicológica anteriormente.

Godoy e Noronha (2005) realizaram pesquisa semelhante, porém com foco específico na área de seleção de pessoas. Obtiveram como resultado, a partir de 15 psicólogos pesquisados, o teste Palográfico como o $4^{\circ}$ mais conhecido, lembrado por 10 profissionais, e o teste PMK como o $7^{\circ}$ mais conhecido, citado por 9 profissionais. O Zulliger, entretanto, figura como $23^{\circ}$ na listagem, com 4 citações, e o Pfister em $41^{\circ}$, citado somente duas vezes. É importante sinalizar, também, que os instrumentos citados nos estudos prévios e neste como os mais conhecidos e usados são ferramentas antigas que, em sua maioria, não possuem recursos atualizados no que tange à validade e fidedignidade.

Com relação à entrevista, instrumento obrigatório na avaliação para porte de arma de fogo conforme Ordem de Serviço $n^{\circ}$ 001/2004 emitida pelo Ministério da Justiça e a Polícia Federal, esta conta com um questionário específico, proposto pela própria comissão da Polícia Federal. Com relação ao formulário de perguntas elaborado pela Polícia Federal, duas psicólogas explicitaram que este contém frases a serem completadas. Uma psicóloga pontuou, ainda, que a entrevista fornecida é superficial, sendo necessários aprofundamentos e uso de outros instrumentos para melhor avaliar o candidato em questão. A afirmação anterior representa o que chamamos de validade clínica, em que o conjunto das informações obtidas sobre o sujeito no processo de avaliação, pelos procedimentos e instrumentos utilizados, dizem respeito a ele independente do contexto em que se encaixam (Tavares, 2003).

Para sete profissionais entrevistadas, o principal ponto a ser abordado na entrevista é a necessidade do conhecimento da motivação para o porte de arma para o candidato e sua relação anterior com armas de fogo. Quatro psicólogas citaram a importância de se verificar o histórico do candidato ao porte com outros armamentos ou portes anteriores, em caso de renovação. Para cinco psicólogas, outro ponto importante a ser questionado é a situação de saúde e uso de substâncias psicoativas ou medicamentos. $\mathrm{O}$ contexto de vida do candidato, sua família e ambiente de trabalho foram citados por 12 das entrevistadas como pontos relevantes a serem questionados.

É feita entrevista com os candidatos e quando eles vem para o porte de arma para pessoa física tem um outro questionário que a gente aplica que a Polícia Federal indica, que é como frases incompletas, inicios de algumas frases que os candidatos precisam estar completando. O foco é 
a utilização dessa arma, verificar se o candidato já teve algum antecedente que ele teve que utilizar a arma ou se é a primeira vez. Verificar a motivação dele, principalmente no caso de pessoa física a motivação dele para ter essa arma, porque quando ele vai trabalhar o porte é funcional, ele vai usar a arma só enquanto está trabalhando. Mas pra pessoa física a gente foca muito no motivo. (Participante 01, 17 anos de formação)

Vida pessoal, vida profissional, vida social, relacionamento familiar, tem sempre aquela coisa das qualidades e dos defeitos, dependendo de como você coloca, fica bem diferente. A gente sempre pergunta um pouco como ela lida com as situações mais complexas, pra ver como ela lida com as situações e os dados pessoais. E por que a necessidade da arma de fogo, porque ela precisa da arma, relaciona com a questão profissional (...) O federal já sai um pouco disso, não dizendo que se restringe mais a essa ou aquela pessoa, mas são pessoas com renda um pouco maior, então porque que elas precisam, porque tem sítio, tem fazenda, né, ou pratica tiro, porque ai você pode carregar a arma desmontada. É, mas assim, pode ter algum problema, ai a pessoa já tira o porte até por isso. Mas é isso que eu tenho mais visto, pessoas que tem algum bem, e é para proteção. (Participante 05, 23 anos de formação)

Dentre as características pessoais dos candidatos que mais levam a concessão de parecer inapto pelos psicólogos peritos figuram a Agressividade (citada por 11 psicólogas), a Instabilidade, (seis profissionais), a Impulsividade (cinco profissionais), os traços de Depressão (três profissionais) e a Ansiedade e a Baixa Sociabilidade (duas profissionais). Segundo Pellini (2006), os indicadores de imaturidade emocional, referidos pelos sintomas citados acima, são a principal causa de reprovações nas avaliações para porte de arma de fogo.

Finalmente, em relação aos principais desafios encontrados na área de Avaliação Psicológica para o porte de arma de fogo foram citados a dificuldade de contato com as psicólogas da Polícia Federal (duas menções), o descrédito por parte dos candidatos (seis menções) e a falta de profissionalismo dos psicólogos que realizam a avaliação (sete menções). Noronha (2002) frisa que problemas de cunho ético são recorrentes na Avaliação Psicológica, principalmente em relação ao desconhecimento dos profissionais que os utilizam.

O descrédito por parte dos candidatos frente à Avaliação Psicológica pode explicitar uma atitude negativa frente ao processo de AP, que é passível de interpretação como um atraso ao alcance do emprego ou um processo de execução difícil. Ainda que sete participantes relatassem levar em conta a subjetividade dos candidatos no decorrer da avaliação, percebeu-se que esta atitude estava mais ligada ao medo de represálias na ocorrência de reprovação que ao bem-estar psicológico necessário para se realizar a bateria de testagem. Percebe-se a importância da maior divulgação dos benefícios da realização da Avaliação Psicológica e sua reafirmação como processo válido e reconhecido para o conhecimento de fenômenos psicológicos, ainda que na própria profissão existam disputas entre diferentes correntes e a aplicabilidade dos testes psicológicos como instrumentos de medida seja constantemente questionada.

\section{Considerações Finais}

É necessário destacar que este trabalho apresenta a limitação de ser realizado em somente um Estado brasileiro, sendo necessárias novas pesquisas de caráter exploratório a fim de ampliar o alcance dos dados aqui verificados. Em consideração ao número de peritos nos diferentes estados, o mapeamento das competências e práticas possibilita a criação de padrões de atuação, a fim de garantir a qualidade das praticas profissionais realizadas, além de promover maior segurança à sociedade quanto à concessão de armamentos aos policiais e à população em geral.

A discussão do papel da Psicologia perante a sociedade, se como compromisso ou como responsabilidade social (Yamamoto, 2012), 
tem respaldo considerando aspectos éticos e as implicações para a segurança da população, como no caso do objeto de estudo deste artigo: Porte de Arma de Fogo. Ainda que uma das principais questões existentes no Brasil com relação aos armamentos seja o comércio e a utilização ilegal, a importância dos procedimentos de avaliação e certificação para uso destes artefatos também se faz necessário. Uma vez que, para o combate à criminalidade, a força policial e serviços de segurança necessitam fazer uso de armas de fogo, inclui-se como papel da Psicologia atuar de forma a propiciar uma avaliação psicológica de qualidade, que ateste as capacidades dos ingressantes nas esferas de segurança pública para a plena condição de cumprir suas funções.

A atuação da peritagem como tarefa secundária e a falta de artigos científicos que abarquem a temática mostram a menor exposição do assunto tanto no âmbito profissional quanto da produção de conhecimentos. Ainda que haja um contingente de profissionais peritos, observa-se um distanciamento entre a prática e o saber profissional na área, fato que promove ações individualizadas ao invés de um conhecimento que possa ser generalizado e aplicado em diferentes localidades.

O aumento da carga horária para o estudo da Avaliação Psicológica e a maior interação entre prática profissional e a teoria poderão auxiliar os psicólogos na obtenção de bases mais seguras de atuação profissional, não somente para o campo da Avaliação Psicológica, mas para a atuação do psicólogo em todos os seus contextos. A maior conscientização do uso de instrumentos psicológicos, uma vez que figuram como privativos do psicólogo, também contribuirá para a disseminação de melhores práticas. 


\section{Julia Carolina Rafalski}

Mestre em Psicologia pela Universidade Federal do Espírito Santo, Vitória - ES. Brasil. E-mail: jcrafalski@gmail.com

\section{Alexsandro Luiz de Andrade}

Doutor em Psicologia pela Universidade Federal do Espírito Santo, Vitória - ES. Brasil. Docente da Universidade Federal do Espírito Santo, Vitória - ES. Brasil.

E-mail: alexsandro.deandrade@yahoo.com

\section{Endereço para envio de correspondência:}

Universidade Federal do Espírito Santo. Programa de Pós-Graduação em Psicologia. Av. Fernando Ferrari, 514. Goiabeiras. CEP: 29075-910. Vitória - ES. Brasil.

Recebido 22/06/2013, Aprovado 08/04/2015. 


\section{Referências}

Almeida, L. S. (1999). Avaliação psicológica: Exigências e desenvolvimentos nos seus métodos. In S. M. Wechsler \& R. S. L. Guzzo (Orgs.), Avaliação psicológica: Perspectiva internacional (pp. 41-55). São Paulo: Casa do Psicólogo.

Bardin, L. (1994). Análise de conteúdo. Lisboa: Edições 70.

Bernardes, J. S. (2012). A formação em psicologia após 50 anos do Primeiro Currículo Nacional da Psicologia: Alguns desafios atuais. Psicologia: Ciência e Profissão, 32(spe), 216-231.

Conselho Federal de Psicologia (CFP). (2000). Resolução CFP $n^{\circ}$ 12/2000, de 20 de dezembro de 2000. Institui o Manual para Avaliação Psicológica de candidatos à Carteira Nacional de Habilitação e condutores de veículos automotores. Brasília, DF: Autor.

Conselho Federal de Psicologia (CFP). (2007). Resolução CFP $n^{\circ}$ 013/2007. Institui a Consolidação das Resoluções relativas ao Título Profissional de Especialista em Psicologia e dispõe sobre normas e procedimentos para seu registro. Brasília, DF: Autor.

Conselho Federal de Psicologia (CFP). (2008). Resolução CFPn ${ }^{\circ}$ 18/2008, de 9 de dezembro de 2008. Dispõe acerca do trabalho do psicólogo na avaliação psicológica para concessão de registro e/ou porte de arma de fogo. Brasília, DF: Autor.

Cotrim, G. (2002). História global: Brasil e geral (6a ed. ref.) São Paulo, SP: Saraiva.

Cruz, R. M. (2004). A avaliação psicológica como um processo de conhecer. In J. C. Alcheiri, \& R. M. Cruz (Orgs.), Avaliação e medida psicológica (pp. 12-21). São Paulo: Casa do Psicólogo.

Dagostin, C. G. (2006). Características do processo de trabalho dos psicólogos peritos examinadores de trânsito na avaliação das condições psicológicas para dirigir. Florianópolis. Dissertação de Mestrado. Programa de PósGraduação em Psicologia. Universidade Federal de Santa Catarina, Florianópolis.

Godoy, S. L., \& Noronha, A. P. (2005). Instrumentos psicológicos utilizados em seleção profissional. Revista do Departamento de Psicologia UFF, 17(1), 139-159.

Joly, M. C. R. A.; Berberian, A. A.; Andrade, R. G., \& Teixeira, T. C. (2010). Análise de teses e dissertações em avaliação psicológica disponíveis na BVS-PSI Brasil. Psicologia: Ciência e Profissão, 30(1), 174-187.

Lei $n^{\circ} 4.119$, de 27 de agosto de 1962. Dispõe sobre os cursos de formação em Psicologia e regulamenta a profissão de psicólogo. Diário Oficial da União. 17 de dezembro de 1962.

Lei $n^{\circ}$ 9.437, de 20 de fevereiro de 1997. Institui o Sistema Nacional de Armas - SINARM, estabelece condições para o registro e para o porte de arma de fogo, define crimes e dá outras providências. Diário Oficial da União. 25 de fevereiro de 1997.

Lein ${ }^{\circ} 10.826$, de 22 dedezembrode 2003. Dispõe sobre registro, posse e comercialização de armas de fogo e munição, sobre o Sistema Nacional de Armas - Sinarm, define crimes e dá outras providências. Diário Oficial da União. 23 de dezembro de 2003.

Noronha, A. P. P. (2002). Os problemas mais graves e mais frequentes no uso dos testes psicológicos. Psicologia: Reflexão e Crítica, 15(1), 135-142.

Noronha, A. P. P., Beraldo, F. N. M, \& Oliveira, K. L. (2003). Instrumentos psicológicos mais conhecidos e utilizados por estudantes e profissionais de psicologia. Psicologia Escolar e Educacional, 7(1), 47-56.

Noronha, A. P. P., \& Alchieri, J. C. (2004). Conhecimento em avaliação psicológica. Revista Estudos de Psicologia, 21(1), 43-52.

Ocampo, M. L. S. D., Arzeno, M. E. G., \& Piccolo, E. G. (1981). O processo psicodiagnóstico e as técnicas projetivas (11a ed., M. Felzenszwalb, trad.). São Paulo, SP: Martins Fontes.

Pasquali, L. (2009). Psicometria: Teoria dos testes na psicologia e na educação (3a ed.). Petrópolis, RJ: Vozes.

Pellini, M. C. B. M. (2006). Indicadores do Método de Rorschach para avaliação da maturidade emocional para porte de arma de fogo. Tese de Doutorado. Instituto de Psicologia, Universidade de São Paulo. 
Polícia Federal. (2013). Sistema Nacional de Armas - SINARM. Recuperado em 13 de junho de 2013 de http://www.dpf.gov.br/ servicos/armas/

Primi, R. (2010). Avaliação Psicológica no Brasil: Fundamentos, situação atual e direções para o futuro. Psicologia: Teoria e Pesquisa, 26(esp), 25-35.

Primi, R. (2003) Inteligência: Avanços nos modelos teóricos e nos instrumentos de medida. Avaliação Psicológica, 2, 67-77.

Reppold, C. T., \& Serafini, A. J. (2010). Novas tendências no ensino da avaliação psicológica. Avaliação Psicológica, 9(2), 323-329.
Tavares, M. (2003). Validade clínica. Psico-USF, $8(2), 125-136$.

Tavares, M. (2012). Considerações preliminares à condução de uma avaliação psicológica. Avaliação Psicológica, 11(3), 321-334.

Trevizan, M. J. (2011). Contextos em que a avaliação se insere. In Conselho Federal de Psicologia. Ano da avaliação psicológica: Textos geradores (pp. 121-125). Brasília: Conselho Federal de Psicologia.

Yamamoto, O. H. (2012). 50 anos de profissão: responsabilidade social ou projeto éticopolítico? Psicologia: Ciência e Profissão, 32, 6-17. 